\title{
Bioavailability of a Nanoemulsion of Lutein is Greater than a Lutein Supplement
}

\author{
Rohini Vishwanathan, Thomas A. Wilson, and Robert J. Nicolosi* \\ Department of Clinical Laboratory and Nutritional Sciences, Center for Health and Disease Research, University of Massachusetts \\ Lowell, Lowell, MA
}

*Corresponding author. Email: nicolosi.robert@yahoo.com

\begin{abstract}
Lutein, a lipid soluble, oxygenated carotenoid, has shown beneficial effects against the risk factors associated with age-related macular degeneration, cardiovascular disease and also damaging UV radiation. The goal of the present study was to formulate lutein into a stable hydrophilic nanoemulsion that is more bioavailable and consumable in a matrix such as a beverage rather than just supplements. A Microfluidizer ${ }^{\circledR}$ Processor was used to convert an oil-in-water lutein emulsion into a nanoemulsion that is a stable water dispersion and measures $150 \mathrm{~nm}$. After a one wk baseline phase, subjects consumed a lutein supplement pill followed by a lutein nanoemulsion added to orange juice $(6 \mathrm{mg} / \mathrm{d}$ and $2 \mathrm{mg} / \mathrm{d}$ in two separate studies) for one wk each with a $2 \mathrm{wk}$ washout phase between treatments. In study 1 , mean serum lutein concentrations $(\mathrm{n}=9)$ increased by $104 \%(\mathrm{P}<0.001)$ and $167 \%(\mathrm{P}<0.001)$ after the 6 mg supplement and nanoemulsion phases, respectively. In study 2, mean serum lutein concentrations $(\mathrm{n}=11)$ increased by $37 \%(\mathrm{P}<0.05)$ and $75 \%(\mathrm{P}<$ 0.001 ) after the $2 \mathrm{mg}$ lutein supplement and nanoemulsion phases, respectively Despite the fact that the actual concentration of lutein in the $6 \mathrm{mg}$ and $2 \mathrm{mg}$ nanoemulsions was $10 \%$ and $40 \%$ lower compared to the supplement form, respectively, due to Microfluidizer ${ }^{\circledR}$ processor preparation loss, the nanoemulsions resulted in $31 \%(\mathrm{P}<0.05)$ and $28 \%(\mathrm{P}<0.05)$ greater serum lutein concentrations compared to the supplement.. In conclusion, nanoemulsions of lutein had significantly greater bioavailability than the supplement-pill forms.
\end{abstract}

Keywords: Lutein; Nanoemulsions; Supplements; Age-related macular degeneration; Macular pigment; Bioavailability

Citation: R. Vishwanathan, et al. Bioavailability of a Nanoemulsion of Lutein is Greater than a Lutein Supplement. Nano Biomed Eng $2009 ;$ 1(1) : 38-49. DOI: 10.5101/nbe.v1i1.p38-49

\section{Introduction}

Lutein, an oxygenated carotenoid protects against age-related macular degeneration (AMD), the leading cause of vision loss in a population aged $60 \mathrm{y}$ and older $[1,2]$. Lutein together with zeaxanthin and mesozeaxanthin forms macular pigment, which filters damaging blue $(450 \mathrm{~nm})$ radiation of sunlight from reaching the retinal cells [3]. Lutein being an antioxidant also protects the retinal pigment epithelial cells from reactive oxygen species [4]. Lutein may also reduce the risk of coronary heart disease and protect the skin from UV induced damage [5].

Digestibility of the food matrix carrying lutein and its dissolution in lipid micelles affects bioavailability of lutein, which makes plant sources less bioavailable unless processed and/or consumed with a minimum amount of fat [6, 7]. Egg yolks as a source of lutein are more bioavailable than spinach or lutein supplements
[8]. The increased bioavailability of lutein from egg yolks may be attributed to the natural micellar matrix of cholesterol (200 mg/yolk), triglycerides (4 g/yolk) and phospholipids ( $1 \mathrm{~g} /$ yolk) [9]. Egg yolks have been reported to contain an average of 250 to $500 \mu \mathrm{g}$ of lutein and zeaxanthin per yolk [10-11]. The egg yolk micellar particles carrying lutein are 1-2 microns in size (data not shown). In general smaller particle sizes, in the nano range $(50-200 \mathrm{~nm})$ of personal care and cosmetic formulations have been associated with increased bioavailability due to a greater surface to volume ratio [12]. Nanoformulations are also kinetically stable, and when adequately prepared can have a long shelf life [12]. Our lutein nanoemulsion generated by Microfluidizer® Processor technology (patent pending) is a cholesterol-free, oil-in-water emulsion, with particle sizes ranging from $100-150 \mathrm{~nm}$, comprised of soybean oil and a phospholipid emulsifier that converts the normally hydrophobic 
lutein molecule into a stable water dispersion. Nanoemulsions have a hydrophobic core unlike liposomes, which have an aqueous core due to the bilayer configuration of polar lipids that are used to form liposomes [13]. Our laboratory has successfully formulated nutrients such as delta-tocopherol [14] and gammatocopherol [15] into stable nanoemulsion water dispersions and demonstrated increased bioavailability compared to microemulsions using animal models. In addition, other labs using nano-preparations of paclitaxel [16], as well as our reported studies have shown increased bioavailability and efficacy of nanoformulations of anti-cancer drugs such as tamoxifen [17] and dacarbazine [18] and anti-inflammatory compounds such as aspirin [19] compared to micro-suspensions using cell culture and animal models.

The objective of this study was to develop (a) a stable water dispersion of lutein that can be added to a beverage and used in addition to or in place of the supplement pill form especially, in an AMD-susceptible older adult population who presently consume lutein supplement pills (b) a nanoemulsion delivery system for lutein that has greater bioavailability than supplementpill form of lutein at equivalent doses. Two forms and doses of lutein: a $6 \mathrm{mg}$ lutein supplement pill (Study 1) and a multivitamin pill containing $2 \mathrm{mg}$ lutein (Study 2) were compared to $6 \mathrm{mg}$ and $2 \mathrm{mg}$ lutein nanoemulsions, respectively, in two separate studies in healthy adults aged $18 \mathrm{y}$ and older.

\section{Materials and Methods}

\subsection{Subjects}

Recruitment was done at the Center for Health and Disease Research, University of Massachusetts Lowell. Staff and students $>18$ y of age were enrolled based on their willingness to consume both lutein interventions (a supplement pill and a nanoemulsion beverage) for one wk each, to avoid eggs for the study duration and to undergo blood draws four times during the course of the study. Written informed consent was obtained from all subjects before start of the study. The use of human subjects for this study was approved by the University of Massachusetts Lowell Institutional Review Board.

\subsection{Study design}

The $5 \mathrm{wk}$ sequential study consisted of four phases. All participants started with a $1 \mathrm{wk}$ baseline period of no intervention followed by a one wk period of consuming the lutein supplement (capsule/tablet). This was followed by a 2 wk washout phase and finally $1 \mathrm{wk}$ of consuming the lutein nanoemulsion beverage. Two different lutein supplements were compared to the nanoemulsion formulation in two separate pilot studies which were done $7 \mathrm{~ms}$ apart. Study 1 utilized a $6 \mathrm{mg}$ lutein supplement (Ocuvite®) Lutein, Bausch \& Lomb, Madison, NJ) whereas study 2 consisted of a multivitamin containing $2 \mathrm{mg}$ of lutein (ICaps MV, Alcon, Fort
Worth, TX). Our objective in the $2 \mathrm{mg}$ study was to evaluate bioavailability at a lower concentration and also use a multivitamin matrix containing lutein, as the majority of the older adult population consumes a multivitamin. The lutein supplement source in study 1 was FloraGLO, a highly purified form of lutein obtained by a patented extraction process from marigold flowers [20].

Subjects refrained from eating eggs or other multivitamins containing lutein and/or zeaxanthin during the entire study period. Baked food products such as cookies, muffins etc. were allowed throughout the study as long as they did not contribute significant amounts of egg yolk. Subjects filled out a $3 d$ diet record once during each phase, which was analyzed using EvaluEat version 1.2 (Copyright (C) Pearson Education Inc.). As an additional measure of compliance subjects were asked to return empty containers that contained the lutein supplement and nanoemulsion beverage.

\subsection{Blood collection}

A $12 \mathrm{~h}$ fasting blood draw was done at the end of each phase and blood was collected in red top vacutainers (no additives). Serum was separated by centrifugation at $1500 \mathrm{x} \mathrm{g}$ for $12 \mathrm{mins}$ at $4^{\circ} \mathrm{C}$ and aliquots were stored at $-80^{\circ} \mathrm{C}$ until analyses.

\subsection{Formulation of lutein interventions}

Lutein supplements: A 1 wk supply of lutein supplements were dispensed into light protective bottles and handed out to the participants at the end of baseline phase. Participants were given written instructions to consume 1 capsule/tablet per day with a meal and return empty containers at the end of the phase.

Lutein nanoemulsions: The nanoemulsion formulations were prepared as batches of $200 \mathrm{~mL}$, which were then pooled together to obtain $2 \mathrm{~L}$ of the nanoemulsion. The procedure for formulating $200 \mathrm{~mL}$ of nanoemulsion was as follows:

$10 \mathrm{~g}$ of food-grade soybean oil, $0.67 \mathrm{~g}$ of Xangold $15 \%$ oil (Cognis, Cincinnati, $\mathrm{OH}$ ) and 12 drops of natural vitamin E oil (Nature's Bounty, Bohemia, NY) were weighed in a sterile $500 \mathrm{ml}$ polypropylene beaker. The above specified quantities were used in order to achieve a lutein concentration of $6 \mathrm{mg}$ in $25 \mathrm{~mL}$ of the nanoemulsion for study 1 . For study 2 , in order to achieve a concentration of $2 \mathrm{mg}$ of lutein in $10 \mathrm{~mL}$ of the nanoemulsion, $0.45 \mathrm{~g}$ of Xangold $15 \%$ oil was used.

The mixture was then heated and stirred in a water bath at $50-60{ }^{\circ} \mathrm{C}$ using a magnetic stirrer until dissolved for about 5 mins.

$8 \mathrm{~g}$ of Phospholipon 85G (Lipoid LLC, Newark, NJ) was then added and the mixture was heated and stirred again at $60{ }^{\circ} \mathrm{C}$ for 5 mins. Phospholipon $85 \mathrm{G}$ was used as it is not toxic to humans and also was shown to produce stable lutein nanoemulsions in pre-clinical studies in our laboratory (unpublished). Natural spring water 
(Poland Springs, Greenwich, CT) was then added to bring the final volume to $200 \mathrm{~mL}$.

The mixture was heated and stirred again for 25 mins at $60{ }^{\circ} \mathrm{C}$ to obtain a homogeneous oil-in-water emulsion.

The emulsion was passed through a small volume high shear Microfluidizer ${ }^{\circledR}$ Processor 110S (Microfluidics Corporation, Newton, MA) once at 22,000 psi. The Microfluidizer, a patent-protected piece of equipment, has a pneumatic intensifier pump, which creates high shear rates by accelerating the sample through microchannels at a high velocity creating submicron sizes particles [14].

The above steps were repeated until $2 \mathrm{~L}$ of nanoemulsion was obtained. Orange juice (Tropicana, Chicago, IL) was used as the mode of delivery of the nanoemulsion because the lutein nanoemulsion formed a homogeneous mixture with the orange juice. The nanoemulsions were added to $10 \mathrm{oz}$. of orange juice after removal of $25 \mathrm{~mL}$ of juice for the $6 \mathrm{mg}$ study and $10 \mathrm{~mL}$ of juice for the $2 \mathrm{mg}$ study. The bottles were shaken well and stored at $4{ }^{\circ} \mathrm{C}$ in brown, light protective bags. The participants were given their supply of beverages for the entire week at the end of the washout phase. Participants were given written instructions to consume one $10 \mathrm{oz}$. bottle of orange juice per day with a meal and to keep the beverages refrigerated.

\subsection{Characterization of lutein nanoemulsions}

The particle size and polydispersity index of the nanoemulsions were measured using a Zetasizer Nano series (Malvern Instruments Inc. Southborough, MA). This device measures particle size using a process called Dynamic Light Scattering (DLS). DLS (also known as PCS - Photon Correlation Spectroscopy) measures Brownian motion and relates this to the size of the particles. It does this by illuminating particles with a laser and analyzing the intensity fluctuations in the scattered light.

\subsection{Serum total and HDL lutein concentration}

Serum collected at the end of each phase for each subject was analyzed at the same time for carotenoids. This was done using an Agilent 1100 model (Agilent technologies, Santa Clara, CA) High Performance Liquid Chromatography (HPLC) apparatus with a Diode Array detector, after $100 \mu \mathrm{L}$ of serum and $200 \mu \mathrm{L}$ of HDL containing serum were extracted as per the procedure described by Handelman et al. [21]. Serum containing HDL was obtained by treatment of $200 \mu \mathrm{L}$ serum with $200 \mu \mathrm{L}$ Trace DMA HDL-precipitating reagent (Thermo Electron, Melbourne, Australia) followed by centrifugation at $5000 \mathrm{rpm}$ for $5 \mathrm{mins}$. The supernatant serum contained HDL while the non-HDL fraction formed a pellet. Concentration of lutein carried on nonHDL fraction was calculated as the difference between serum lutein concentration and HDL-lutein concentration.

The enzyme reagent used for extractions was prepared using Cholesterol esterase and Triacylglycerol lipase (Calbiochem, San Diego, CA) that release carotenoids from the carrier lipoproteins. The internal standard used was Tocol [22]. The HPLC column was a 300 $\mathrm{mm} \times 4.6 \mathrm{~mm}$ Adsorbosphere HS C18 with $3 \mu \mathrm{m}$ particle size and $60 \mathrm{~A}^{\circ}$ pore size (Grace Davidson Discover Sciences, Illinois) that was maintained at $18.5^{\circ} \mathrm{C}$ during analysis. The solvent system comprised of $40 \%$ mobile phase (a mixture of $0.4 \%$ ammonium acetate, $50 \%$ acetonitrile and $50 \%$ methanol) and $60 \%$ pure acetonitrile for the first $20 \mathrm{mins}$ at $1 \mathrm{~mL} / \mathrm{min}$. At $21 \mathrm{mins}, 25 \%$ isopropanol and $60 \%$ acetonitrile were run for $20 \mathrm{mins}$, followed by an equilibration period of 20 mins with initial conditions before the next sample.

\subsection{Nanoemulsion lutein concentration}

Nanoemulsions were extracted to measure the percent recovery of lutein after microfluidization. Aliquots of the lutein nanoemulsion were diluted $(1: 100)$ in $0.1 \mathrm{M}$ phosphate buffer and extracted in a similar manner as serum. Two $\mathrm{mL}$ of $6 \mathrm{~N} \mathrm{KOH}$ was used instead of enzyme reagent and samples were incubated for 30 mins in a $60{ }^{\circ} \mathrm{C}$ water bath followed by extraction with 1:1 hexane-ether [21].

\subsection{Serum lipids and lipoprotein cholesterol}

Serum lipids and lipoprotein cholesterol concentrations were measured using a Cobas Mira Plus Clinical Chemistry Autoanalyzer (Roche, Branchburg, NJ). Serum total cholesterol (TC) [23] concentrations were measured enzymatically using the Infinity Cholesterol Reagent procedure from Thermo Electron (Melbourne, Australia). Serum triglyceride (TG) concentrations [24] were measured enzymatically using InfinityTriglyceride Reagent procedure from Thermo Electron (Melbourne, Australia). Serum HDL cholesterol was measured directly using Infinity HDL Cholesterol Reagent procedure from Thermo Electron (Melbourne, Australia). The concentration of serum LDL cholesterol was calculated via the Friedewald equation. The accuracy and precision of the procedures used for the lipids and lipoprotein cholesterol measurements are maintained by participation in the Lipid Standardization Program of CDC (Atlanta, GA) and the National Heart, Blood and Lung Institute (NHLBI) (Bethesda, MD).

\subsection{Statistical analyses}

Sigma stat version 3.1 (Jandel Scientific, San Rafael, CA), a SPSS statistical software package was used for all data analyses [25]. All serum concentrations are expressed as mean \pm SEM and statistical significance was set at $P<0.05$. Percent changes and any significant effect of lutein interventions were compared to baseline unless stated differently. Differences between the 4 
phases were determined by repeated measures One-way ANOVA. When differences were observed, a Tukey test was used. Pearson Product Moment Correlation was performed to obtain associations between all the variables measured.

\section{Results}

\subsection{Subjects}

Nine participants completed the $6 \mathrm{mg}$ lutein study 1 while 14 participants completed the $2 \mathrm{mg}$ lutein study 2 . The age range of the participants was 25 to $65 \mathrm{y}$ with only one being over $60 \mathrm{y}$. Data from 3 participants in study 2 were excluded for the following reasons. One participant consumed more than 3 eggs at baseline, one could only complete $5 \mathrm{ds}$ of both the lutein interventions instead of $7 \mathrm{ds}$ and the third participant did not normally consume orange juice hence lutein nanoemulsion was added to apple juice for this participant. However, during the course of the study creaming effect occurred in the apple juice containing the nanoemulsion unlike the orange juice. This indicated that the nanoemulsion was unstable in apple juice and thus may not have had the same biological effect as the nanoemulsion in orange juice.

\subsection{Diet data}

Diet data showed there were no significant differences in mean macronutrient intake across the four phases (data not shown). Amongst the micronutrients, vitamin B6 intake decreased significantly during the lutein supplement and nanoemulsion phases. This was accompanied by a simultaneous decrease in niacin dur- ing the nanoemulsion phase but not the supplement phase as one lutein containing multivitamin tablet had $2.5 \mathrm{mg}$ niacin. Although the 7DDR analysis program did not calculate carotenoid intake, the diet records were reviewed to evaluate lutein and zeaxanthin rich foods consumed during the four phases. Spinach, broccoli and corn were the only other foods frequently consumed during the study that had substantial amounts of lutein and zeaxanthin [26]. The mean intakes of these foods were not significantly different between the four phases (data not shown).

\subsection{Particle size of lutein nanoemulsions}

The average particle sizes (Z-average size) of the 6 $\mathrm{mg}$ and $2 \mathrm{mg}$ lutein nanoemulsions used in studies 1 and 2 , respectively, were $155 \mathrm{~nm}$ and $157 \mathrm{~nm}$ respectively (Figure 1a). Particle sizes of the nanoemulsions were stable for a period of up to 6 months when stored at $4^{\circ} \mathrm{C}$ with a polydispersity index (PDI), a width parameter, of less than 0.2 (Figure 1b). Z-average measurements are unreliable for broader measurements where the PDI is over 0.5 .

Particle size analysis of lutein microemulsion, before microfluidization process, was performed and showed a non-homogeneous mixture with $\mathrm{Z}$-average of about 3 microns and PDI of 1.000 (Figure 1c). The lutein microemulsion was also highly unstable as creaming was observed in $24 \mathrm{~h}$ and hence was not used as an intervention for the study. Particle size graphs of the $6 \mathrm{mg}$ lutein nanoemulsion are shown as an example in Figure 1.

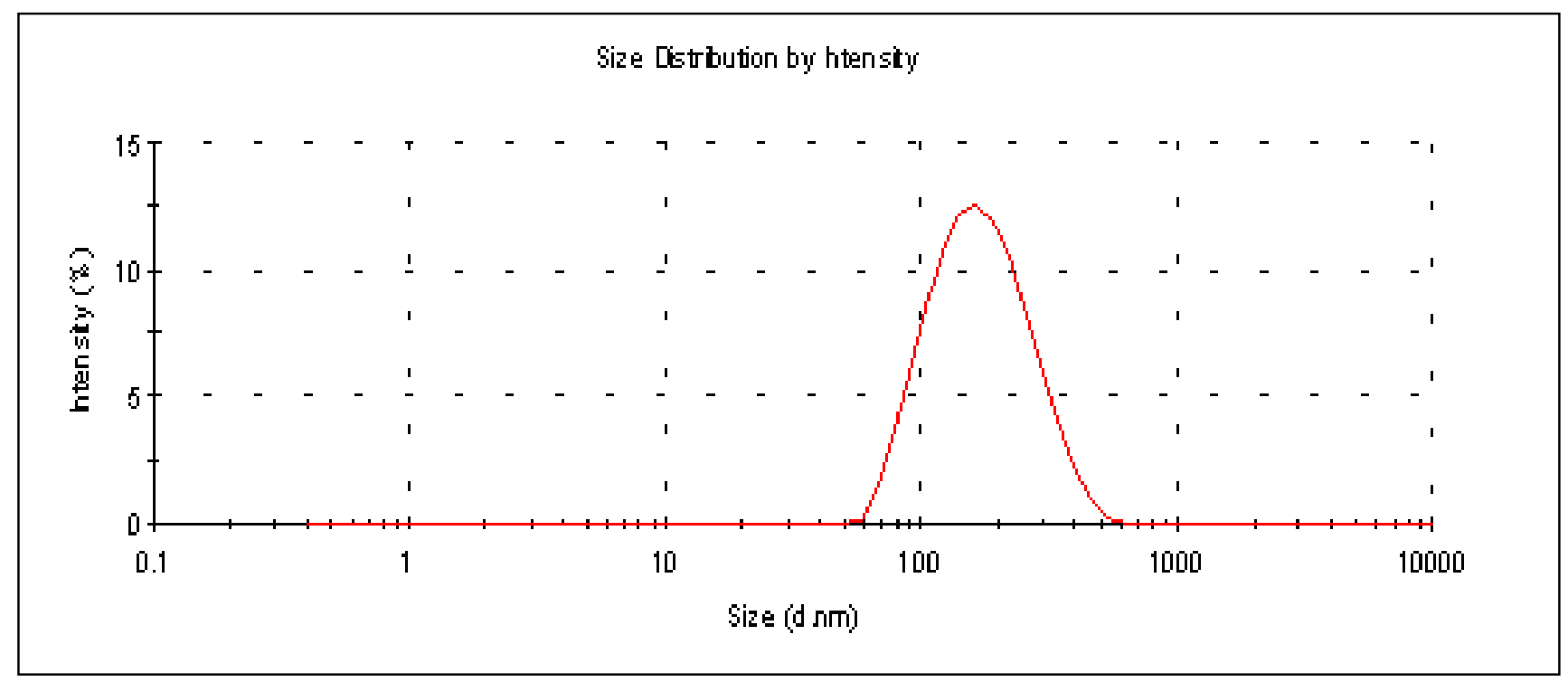

Figure 1.a Particle size graph of the $6 \mathrm{mg}$ lutein nanoemulsion measured using dynamic laser light scattering (DLS) at the start of the study showing an average particle size of $155 \mathrm{~nm}$ with a PDI=0.157. 


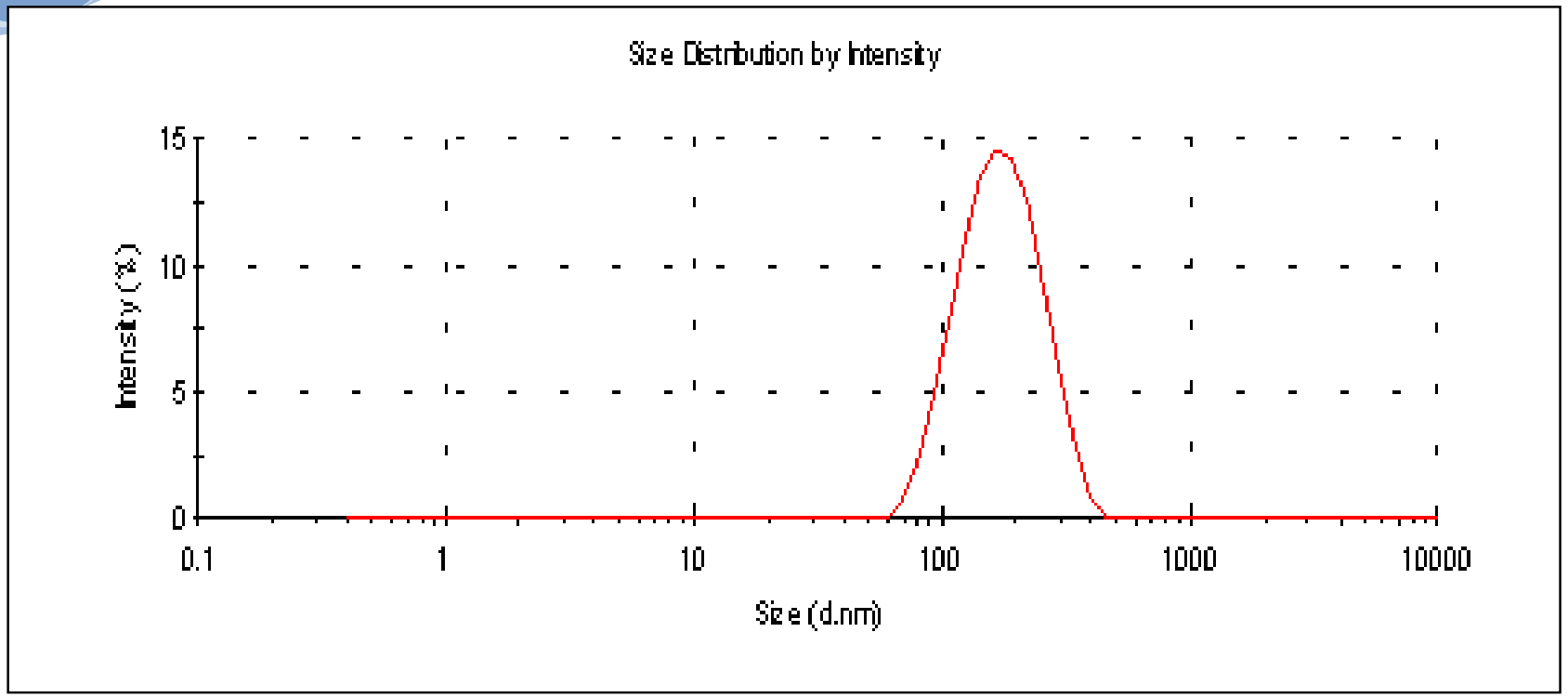

Figure 1.b Particle size graph of the $6 \mathrm{mg}$ lutein nanoemulsion measured using dynamic laser light scattering (DLS) 6 months post study period showing an average particle size of $153.2 \mathrm{~nm}$ with a PDI= 0.143 .

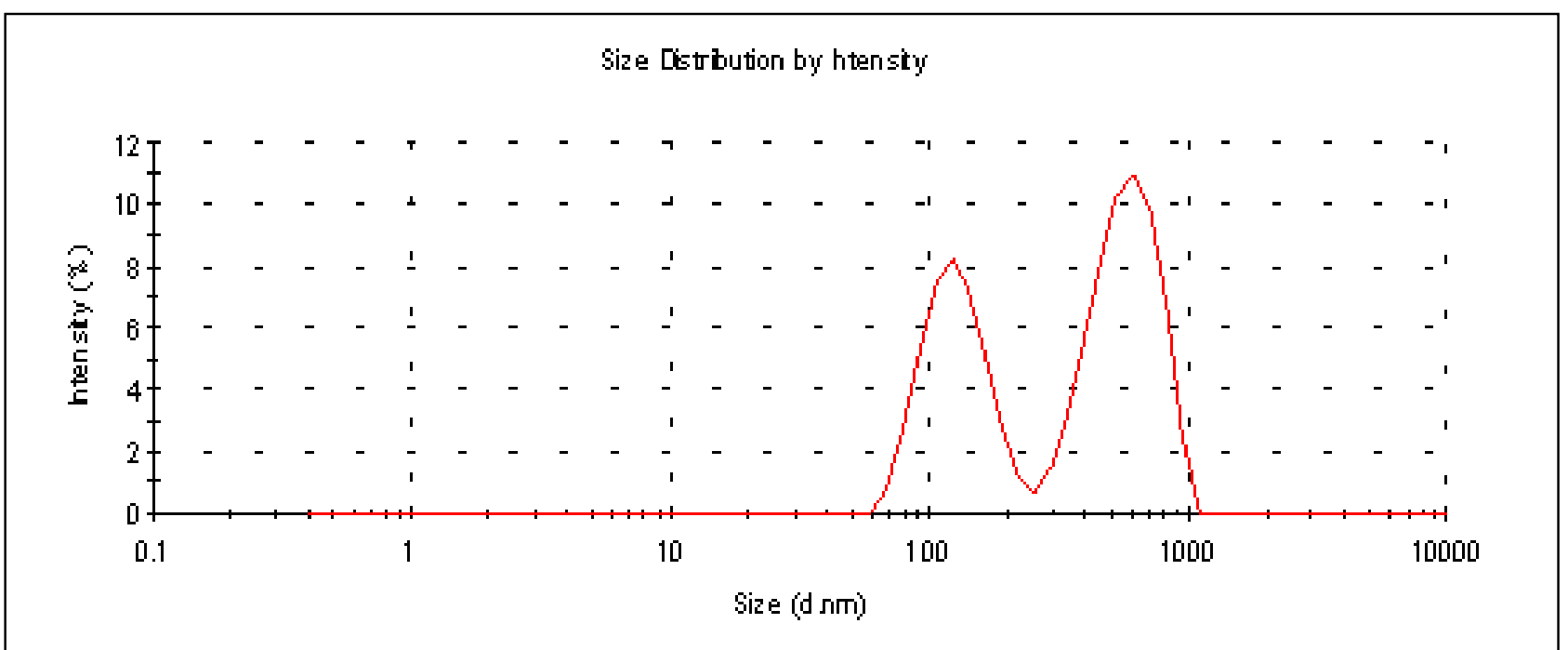

Figure 1.c Particle size graph of a lutein microemulsion (lutein formulation pre-microfluidization) measured using dynamic laser light scattering (DLS) showing an average particle size of $3449 \mathrm{~nm}$ with a PDI=1.000. The presence of multiple peaks indicates a non-homogeneous mixture.

\subsection{Concentration of lutein and zeaxanthin in the nanoemulsion}

In study 1, the actual concentration of lutein in the 6 mg nanoemulsion $(\mathrm{n}=6)$ was $218 \mu \mathrm{g} / \mathrm{mL}$, which corresponds to $5.45 \mathrm{mg}$ per $25 \mathrm{~mL}$ of the nanoemulsion. The supplement used for this study had $6 \mathrm{mg}$ of lutein per capsule. Thus, lutein concentration in the $6 \mathrm{mg}$ nanoemulsion was $10 \%$ lower than lutein in the supplement.

Unexpectedly, in study 2, the actual concentration of lutein in the $2 \mathrm{mg}$ nanoemulsion $(\mathrm{n}=4)$ was 100 $\mu \mathrm{g} / \mathrm{mL}$, which corresponds to $1 \mathrm{mg}$ per $10 \mathrm{~mL}$ of nanoemulsion. The supplement used for this study had $6.67 \mathrm{mg}$ lutein in one serving (4 tablets) and participants consumed 1 tablet per day, which is equivalent to 1.7 $\mathrm{mg}$ lutein per day. Thus, lutein concentration in the 2 $\mathrm{mg}$ nanoemulsion was $40 \%$ lower than lutein in the supplement.

The zeaxanthin levels in the $6 \mathrm{mg}$ supplement of study 1 were not reported in the product information sheet while the $2 \mathrm{mg}$ supplement of study 2 reported $3.33 \mathrm{mg}$ in 4 tablets i.e. $833 \mu \mathrm{g}$ zeaxanthin per tablet. The $6 \mathrm{mg}$ nanoemulsion used in study 1 had $422 \mu \mathrm{g}$ zeaxanthin per $10 \mathrm{oz}$. of orange juice while the $2 \mathrm{mg}$ 


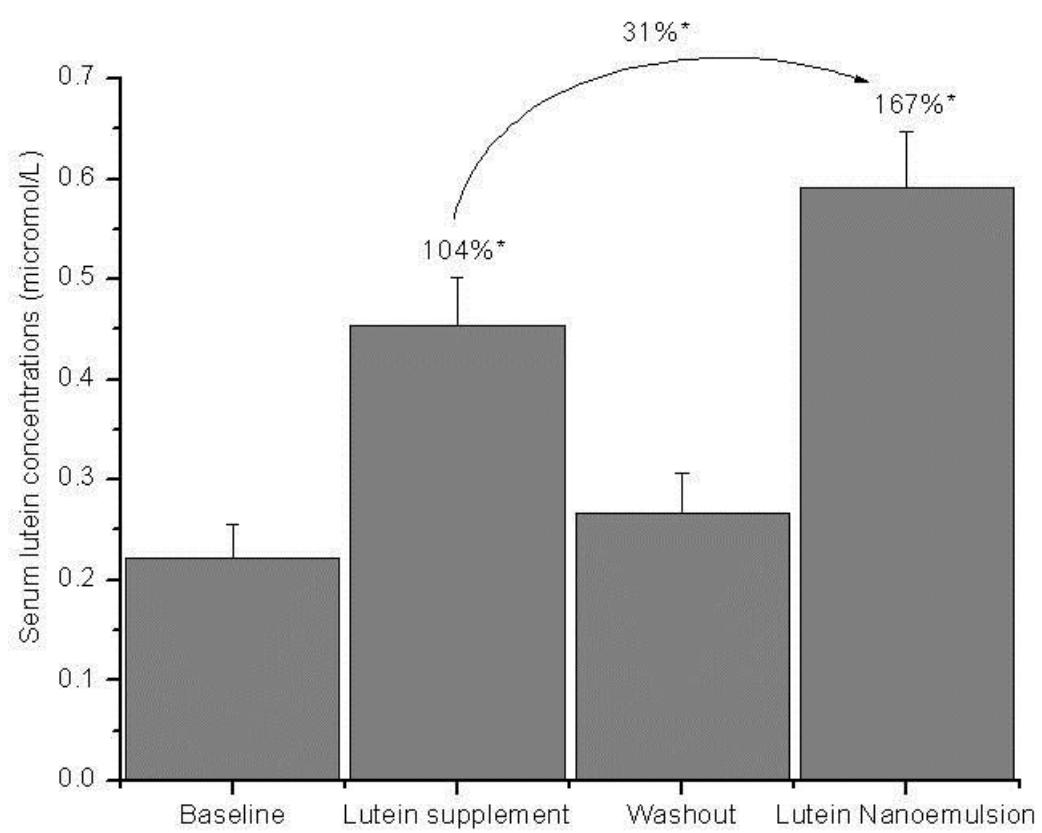

$* P<0.001$ using One-way RM ANOVA followed by Tukey test

Figure 2.a Mean \pm SEM serum lutein concentrations $(\mu \mathrm{mol} / \mathrm{L})$ at baseline, lutein supplement $(6 \mathrm{mg} / \mathrm{d})$, washout and lutein nanoemulsion $(6 \mathrm{mg} / \mathrm{d})$ phases in study 1 with percent differences between baseline-lutein supplement, baseline-lutein nanoemulsion and lutein supplement-nanoemulsion phases. $\mathrm{n}=9$.

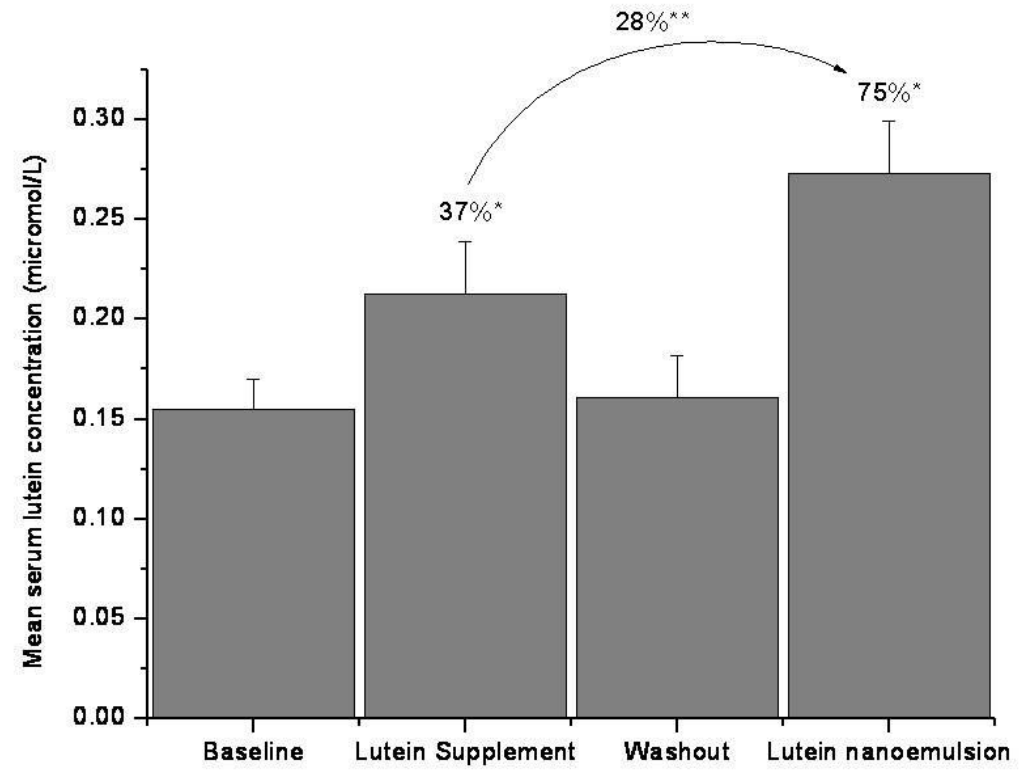

$* P<0.001, * * P<0.050$ using One-way RM ANOVA followed by Tukey test

Figure 2.b Mean \pm SEM serum lutein concentrations $(\mu \mathrm{mol} / \mathrm{L})$ at baseline, lutein supplement $(2 \mathrm{mg} / \mathrm{d})$, washout and lutein nanoemulsion $(2 \mathrm{mg} / \mathrm{d})$ phases in study 2 with percent differences between lutein supplement-baseline, lutein nanoemulsion-baseline and lutein supplement-nanoemulsion phases. $\mathrm{n}=11$ 


\subsection{Serum lutein concentration}

Nanoemulsion used in study 2 had approximately 18 $\mu \mathrm{g}$ of zeaxanthin. In study 1 , mean serum lutein concentration increased by $104 \%(P<0.001)$ and $167 \%(P<$ 0.001 ) after one wk of consuming $6 \mathrm{mg}$ lutein per day of supplement and nanoemulsion, respectively, compared to baseline (Figure 2a). There was a $31 \%(P<$ 0.05 ) increase in serum lutein concentration during the nanoemulsion phase compared to the supplement phase.

In study 2 , mean serum lutein concentration increased by $37 \%(P<0.05)$ and $75 \%(P<0.001)$ after one wk of consuming $2 \mathrm{mg}$ lutein per day of the supplement and nanoemulsion, respectively, compared to baseline (Figure $2 \mathrm{~b}$ ). There was a $28 \%(P<0.05)$ increase in serum lutein concentration during the nanoemulsion phase compared to the supplement phase.

Individual responses of serum lutein concentrations to both the interventions are shown in Table 1. Three participants in the $2 \mathrm{mg}$ study and one in the $6 \mathrm{mg}$ study showed slightly lower $(<10 \%)$ serum lutein response to nanoemulsion compared to the supplement. However, the mean serum lutein concentration of these 4 participants during the supplement phase $(0.338 \pm 0.095$ $\mu \mathrm{mol} / \mathrm{L}$ ) was not significantly greater than during the nanoemulsion phase $(0.307 \pm 0.091 \mu \mathrm{mol} / \mathrm{L})$. Participant $\mathrm{AE}$ missed one serving of the lutein nanoemulsion.

\subsection{Serum zeaxanthin, $\alpha$-carotene and $\beta$-carotene concentrations}

Mean serum zeaxanthin concentration increased by $66 \%(P<0.001)$ and $83 \%(P<0.001)$ after the $6 \mathrm{mg}$ lutein supplement and nanoemulsion phases, respectively, in study 1 compared to baseline. In study 2 , an increase of $46 \%(P<0.001)$ and $19 \%$ was observed in mean serum zeaxanthin concentration after the $2 \mathrm{mg}$ lutein supplement and nanoemulsion phases respectively.

In study 1 with 6 mg lutein, mean serum $\beta$-carotene concentration was lowest during the lutein supplement phase (Table 2) with a $30 \%(P<0.05)$ increase after the nanoemulsion phase compared to baseline. Mean serum $\alpha$-carotene concentrations did not change during any of the phases in both the studies.

Table 1. Individual serum lutein concentrations $(\mu \mathrm{mol} / \mathrm{L})$ at baseline, lutein supplement and lutein nanoemulsion phases of study participants from both study 1 (6 mg lutein) and study 2 ( $2 \mathrm{mg}$ lutein).

\begin{tabular}{cccccccc}
\hline Participants & Sex & Baseline & $\begin{array}{c}\text { Lutein sup- } \\
\text { plement } \\
(6 \mathrm{mg} / \mathrm{d})\end{array}$ & $\begin{array}{c}\text { Lutein } \\
\text { Nanoemulsion } \\
(6 \mathrm{mg} / \mathrm{d})\end{array}$ & $\begin{array}{c}\text { Baseline } \\
\text { Lutein sup- } \\
\text { plement } \\
(2 \mathrm{mg} / \mathrm{d})\end{array}$ & $\begin{array}{c}\text { Lutein } \\
\text { Nanoemulsion } \\
(2 \mathrm{mg} / \mathrm{d})\end{array}$ \\
\hline RV & F & 0.224 & 0.327 & 0.561 & 0.275 & 0.332 & 0.404 \\
LK & F & 0.181 & 0.386 & 0.616 & 0.124 & 0.199 & 0.339 \\
TW & M & 0.212 & 0.345 & 0.537 & 0.159 & 0.235 & 0.302 \\
RN & M & 0.080 & 0.621 & 0.733 & - & - & - \\
SRI & M & 0.185 & 0.279 & 0.556 & 0.119 & 0.092 & 0.162 \\
JX & M & 0.290 & 0.592 & 0.555 & - & - & - \\
NP & M & 0.250 & 0.390 & 0.491 & - & - & - \\
RL & M & 0.441 & 0.694 & 0.937 & - & - & - \\
AE & M & 0.136 & 0.440 & 0.331 & - & - & - \\
RB & F & - & - & - & 0.164 & 0.231 & 0.354 \\
KD & F & - & - & - & 0.076 & 0.130 & 0.140 \\
SK & F & - & - & - & 0.152 & 0.297 & 0.208 \\
RR & M & - & - & - & 0.200 & 0.253 & 0.287 \\
DAS & M & - & - & - & 0.156 & 0.121 & 0.191 \\
KG & F & - & - & - & 0.166 & 0.332 & 0.323 \\
SE & F & - & - & - & 0.120 & 0.124 & 0.287 \\
\hline
\end{tabular}

Mean serum lutein concentration after baseline and washout phases were the same. 
3.7 HDL and non-HDL distribution of lutein

The distribution of lutein between the HDL and non-HDL fractions in serum did not change during the supplement and nanoemulsion interventions in both studies 1 and 2 containing $6 \mathrm{mg}$ and $2 \mathrm{mg}$ lutein, respectively (Table 3).

In study 1 , mean HDL-lutein concentration increased by $87 \%(\mathrm{P}<0.001)$ and $137 \%(\mathrm{P}<0.001)$ after the $6 \mathrm{mg}$ supplement and nanoemulsion phases, respectively, compared to baseline while mean non-HDL lute- in concentrations increased by $126 \%(P<0.050)$ and $206 \%(P<0.001)$, respectively.

In study 2, mean HDL-lutein concentration increased by $40 \%$ and $66 \%(P<0.050)$ after the $2 \mathrm{mg}$ supplement and nanoemulsion phases, respectively, compared to baseline while mean non-HDL lutein concentration increased by $31 \%$ and $86 \%(P<0.050)$ respectively.Approximately $40-50 \%$ of zeaxanthin and $12-15 \%$ of $\alpha$-carotene and $\beta$-carotene were carried on HDL during all four phases (data not shown).

Table 2. Mean \pm SEM concentrations in $\mu \mathrm{mol} / \mathrm{L}$ of serum zeaxanthin, $\alpha$-carotene and $\beta$-carotene at baseline, lutein supplement, washout and lutein nanoemulsion phases in both study 1 (6 mg lutein) and study 2 (2 mg lutein).

Baseline $\begin{gathered}\text { Lutein supple- } \\ \text { ment }\end{gathered} \quad$ Washout $\quad \begin{gathered}\text { Lutein } \\ \text { nanoemulsion }\end{gathered}$

\begin{tabular}{|c|c|c|c|c|}
\hline Study 1 & & & & \\
\hline $\begin{array}{l}6 \text { mg study }(\mathbf{n}=9) \\
\text { Serum zeaxanthin }\end{array}$ & $0.062+0.007^{\mathrm{a}}$ & $0.103+0.010^{b}$ & $0.064+0.008^{\mathrm{a}}$ & $0.115+0.011^{\mathrm{b}}$ \\
\hline Serum $\alpha$-carotene & $0.127+0.037$ & $0.115+0.028$ & $0.162+0.033$ & $0.177+0.040$ \\
\hline Serum $\beta$-carotene & $0.323+0.092^{\mathrm{a}, \mathrm{b}}$ & $0.308+0.072^{\mathrm{a}}$ & $0.363+0.080^{\mathrm{a}, \mathrm{b}}$ & $0.401+0.090^{\mathrm{b}}$ \\
\hline $\begin{array}{l}\text { Study } 2 \\
\mathbf{2} \text { mg study }(n=11) \\
\text { Serum zeaxanthin }\end{array}$ & $0.060+0.006^{\mathrm{a}}$ & $0.087+0.010^{b}$ & $0.063+0.006^{\mathrm{a}}$ & $0.071+0.008^{\mathrm{a} . \mathrm{b}}$ \\
\hline Serum $\alpha$-carotene & $0.089+0.010$ & $0.097+0.023$ & $0.077+0.021$ & $0.088+0.026$ \\
\hline Serum $\beta$-carotene & $0.252+0.048$ & $0.268+0.065$ & $0.260+0.069$ & $0.277+0.058$ \\
\hline
\end{tabular}

Table 3. Mean \pm SEM serum lutein concentrations and HDL-lutein concentrations in $\mu$ mol/L with mean percentage of lutein carried on HDL at baseline, lutein supplement, washout and lutein nanoemulsion phases in both study 1 (6 mg lutein) and study 2 ( $2 \mathrm{mg}$ lutein).

\begin{tabular}{lcccc}
\hline & Baseline & $\begin{array}{c}\text { Lutein supple- } \\
\text { ment }\end{array}$ & Washout & $\begin{array}{c}\text { Lutein nanoemul- } \\
\text { sion }\end{array}$ \\
\hline $\begin{array}{l}\text { Study 1 } \\
\mathbf{6} \text { mg study (n=9) }\end{array}$ & $0.222+0.034^{\mathrm{a}}$ & $0.453+0.049^{\mathrm{b}}$ & $0.267+0.040^{\mathrm{a}}$ & $0.591+0.056^{\mathrm{c}}$ \\
$\begin{array}{l}\text { Serum total lutein } \\
\text { Serum HDL-lutein }\end{array}$ & $0.127+0.025^{\mathrm{a}}$ & $0.238+0.035^{\mathrm{b}}$ & $0.160+0.038^{\mathrm{a}}$ & $0.301+0.036^{\mathrm{c}}$ \\
$\begin{array}{l}\text { Percentage lutein carried } \\
\text { on HDL }\end{array}$ & $54.0+4.6$ & $53.6+5.9$ & $56.4+4.1$ & $50.9+2.9$ \\
$\begin{array}{l}\text { Study 2 } \\
\mathbf{2} \text { mg study (n=11) }\end{array}$ & $0.155+0.015$ & $0.213+0.026$ & $0.161+0.021$ & $0.273+0.026$ \\
$\begin{array}{l}\text { Serum total lutein } \\
\text { Serum HDL-lutein }\end{array}$ & $0.092+0.018^{\mathrm{a}}$ & $0.129+0.019^{\mathrm{a}, \mathrm{b}}$ & $0.091+0.010^{\mathrm{a}}$ & $0.153+0.016^{\mathrm{b}}$ \\
$\begin{array}{l}\text { Percentage lutein carried } \\
\text { on HDL }\end{array}$ & $56.9+5.7$ & $60.5+4.3$ & $57.8+2.8$ & $56.4+3.6$ \\
\hline
\end{tabular}

Means not sharing a common superscript are significantly different at $P<0.05$ using One-way RM ANOVA followed by Tukey test. 
Table 4. Mean \pm SEM concentrations of serum total cholesterol, HDL cholesterol, LDL cholesterol and triglycerides in $\mathrm{mmol} / \mathrm{L}$ at baseline, lutein supplement, washout and lutein nanoemulsion phases in both study 1 (6 mg lutein) and study 2 (2 mg lutein).

\begin{tabular}{|c|c|c|c|c|}
\hline & Baseline & Lutein supplement & Washout & $\begin{array}{l}\text { Lutein nanoemul- } \\
\text { sion }\end{array}$ \\
\hline $\begin{array}{l}\text { Study } 1 \\
6 \text { mg study }(\mathbf{n}=9) \\
\text { Total cholesterol }\end{array}$ & $4.34 \pm 0.17$ & $4.52 \pm 0.25$ & $4.58 \pm 0.31$ & $4.33 \pm 0.33$ \\
\hline HDL cholesterol & $1.05 \pm 0.09$ & $1.04 \pm 0.08$ & $1.08 \pm 0.06$ & $1.03 \pm 0.06$ \\
\hline LDL cholesterol & $2.60 \pm 0.16$ & $2.35 \pm 0.26$ & $2.86 \pm 0.22$ & $2.63 \pm 0.20$ \\
\hline Triglyceride & $1.53 \pm 0.27$ & $2.48 \pm 0.96$ & $1.39 \pm 0.25$ & $1.45 \pm 0.37$ \\
\hline $\begin{array}{l}\text { Study } 2 \\
2 \text { mg study }(n=11) \\
\text { Total cholesterol }\end{array}$ & $4.52 \pm 0.28$ & $4.61 \pm 0.30$ & $4.46 \pm 0.26$ & $4.41 \pm 0.31$ \\
\hline HDL cholesterol & $1.18 \pm 0.09$ & $1.24 \pm 0.10$ & $1.20 \pm 0.08$ & $1.16 \pm 0.10$ \\
\hline LDL cholesterol & $2.66 \pm 0.27$ & $2.81 \pm 0.24$ & $2.88 \pm 0.24$ & $2.73 \pm 0.26$ \\
\hline Triglyceride & $1.48 \pm 0.27^{\mathrm{a}}$ & $1.21 \pm 0.20^{\mathrm{a}, \mathrm{b}}$ & $0.85 \pm 0.10^{\mathrm{b}}$ & $1.16 \pm 0.17^{\mathrm{a}, \mathrm{b}}$ \\
\hline
\end{tabular}

\subsection{Serum lipids and lipoprotein cholesterol}

In study 1 , mean serum TC, HDL cholesterol, LDL cholesterol and TG concentrations did not change during any of the phases (Table 4$)$. In study 2 , a $74 \%(P<$ 0.05 ) decrease was observed in serum TG concentration after the washout phase compared to baseline, which may have occurred as some participants were not fasting during the baseline blood draw. No change was observed in serum TC, HDL and LDL cholesterol concentrations (Table 4).

In study 1 , serum lutein concentration was positively associated $(P<0.050)$ with serum HDL cholesterol concentration at the baseline $(\mathrm{r}=0.843)$, lutein supplement $(r=0.757)$, washout $(r=0.894)$ and lutein nanoemulsion $(\mathrm{r}=0.949)$ phases. . In study 2 , serum lutein concentration was associated $(\mathrm{P}<0.050)$ with serum HDL only at baseline $(r=0.784)$ and washout $(r$ $=0.627$ ) phases.

\section{Discussion}

A novel lutein nanoemulsion delivery system was formulated using Microfluidizer ${ }^{\circledR}$ Processor and bioavailability was determined in a pilot-scale clinical study. Nanoemulsion delivery systems have previously been shown to improve bioavailability of nutrients such as delta-tocopherol, calcium and the vitamin-like coenzyme Q-10 molecule [14, 27, 28]. Pre-clinical studies have shown increased anti-cancer activity of drugs such as tamoxifen and dacarbazine, enhanced antiinflammatory property of aspirin, improved bioactivity of insulin when delivered as nanoemulsions [17-19, 29]. Paclitaxel nanoformulation showed increased bioavaila- bility, efficacy and reduced toxicity in a clinical study [30].

Consumption of $6 \mathrm{mg} / \mathrm{d}$ and $2 \mathrm{mg} / \mathrm{d}$ of lutein nanoemulsions in studies 1 and 2 , respectively, increased serum lutein concentrations by $28 \%(P<0.05)$ and $31 \%(P<0.05)$ respectively compared to consumption of similar doses of its non-nano supplement counterparts. It is noteworthy that lutein nanoemulsions had greater bioavailability even though the actual lutein concentration in the $6 \mathrm{mg}$ and $2 \mathrm{mg}$ nanoemulsions were $10 \%$ and $40 \%$ lower compared to the lutein supplement. The significantly greater bioavailability of lutein nanoemulsions could have two explanations: (i) nano-sized lutein particles and (ii) micelle-like matrix of the nano particles. The lutein nanoparticles have a greater probability of being absorbed as they have a greater surface to volume ratio as opposed to lutein in a pill form [31,32]. The $6 \mathrm{mg}$ lutein supplement pill in the present study was in a powder, not oil form. The oil and surfactant matrix which carries lutein in a nanoemulsion resembles a micellar structure and makes lutein, a normally hydrophobic molecule, water dispersible. During digestion, carotenoids and other hydrophobic molecules are solubilized into mixed micelles for absorption by intestinal cells [32]. It remains a speculation whether orally consumed lutein nanoemulsions would reassemble into mixed micelles along with the ingested foods/carotenoids in the intestinal lumen or whether the nano lutein particles have the ability to get directly absorbed by the intestinal mucosal cells as they already have a micelle-resembling structure. The $167 \%$ $(P<0.001)$ increase in serum lutein concentration after the $6 \mathrm{mg}$ nanoemulsion phase was also greater than the $82 \%(P<0.001)$ increase observed in a study by Chung 
et al. after consumption of $6 \mathrm{mg}$ lutein/lutein ester supplement for a $10 \mathrm{~d}$ period [8]. Serum lutein response was $207 \%$ when $8 \mathrm{mg}$ utein was consumed with $36 \mathrm{~g}$ of fat while it was $88 \%$ with $3 \mathrm{~g}$ of fat [33]. In the present study, the $6 \mathrm{mg}$ lutein nanoemulsion contained only $1.25 \mathrm{~g}$ of fat and $1 \mathrm{~g}$ of phospholipid (85\% phosphatidylcholine) per serving while the $2 \mathrm{mg}$ lutein nanoemulsion contained $0.5 \mathrm{~g}$ of fat and $0.4 \mathrm{~g}$ of phospholipid. The lutein interventions were not consumed with any additional fat other than that present in the meal with which they were consumed. The lutein supplements also contained $100 \%$ of daily recommended allowance for vitamin $\mathrm{C}$ so did the lutein nanoemulsions as they were added to orange juice, which has been reported to enhance lutein absorption [34].

Among the four participants who took part in both 6 $\mathrm{mg}$ and $2 \mathrm{mg}$ studies, one participant had a $25 \%$ greater increase in serum lutein concentration with $2 \mathrm{mg}$ lutein nanoemulsion compared to even the $6 \mathrm{mg}$ lutein supplement. This indicates that a nanoemulsion delivery system may be effective in individuals who do not respond to even high dosage of supplements. Pharmacological doses of carotenoids are less effectively absorbed as opposed to physiological doses as carotenoid absorption depends on the amount of mixed micelles produced, which in turn depends on dietary triglycerides [32]. The fact the lutein nanoemulsions were significantly more bioavailable even at $10-40 \%$ lower doses than supplements is indicative that nanoemulsions could increase bioavailability even at physiological doses.

A 1 wk intervention period was sufficient to study serum responses to increased dietary lutein consumption. Molldrem et al [35] also observed increases in serum lutein concentration after one week of feeding a lutein supplement and lutein containing yellow carrots. The fact that serum lutein concentrations decreased to baseline concentration during the $2 \mathrm{wk}$ washout phase is also consistent with past lutein intervention studies $[8,35]$.

In study 1 containing $6 \mathrm{mg}$ of lutein, the supplement was not reported to have any zeaxanthin while the nanoemulsion had about $422 \mu \mathrm{g}$ zeaxanthin/ serving but significant increases were observed after consumption of both interventions compared to baseline. A greater concentration of zeaxanthin ( $833 \mu \mathrm{g} /$ serving) in the 2 $\mathrm{mg}$ supplement compared to the $2 \mathrm{mg}$ nanoemulsion (18 $\mu \mathrm{g} / \mathrm{serving}$ ) may have caused greater increases in serum zeaxanthin after the supplement compared to the nanoemulsion phase. Results from a randomized, blinded, cross-over, lutein intervention study using yellow carrots and lutein supplements, showed a decrease in serum $\beta$-carotene concentration with simultaneous intake of lutein supplements but not with intake of lutein containing yellow carrots [35]. The nanoemulsion intervention also had a similar effect on serum $\beta$-carotene concentration like the yellow carrots in the above mentioned study. Lutein and $\beta$-carotene are known to com- pete with each other for incorporation into chylomicrons; lutein supplemented in a purified form with $\beta$ carotene lowers $\beta$-carotene chylomicron response [36]. Lutein delivered as a nanoemulsion had an advantage as it did not affect $\beta$-carotene absorption. Lutein supplementation of up to $6 \mathrm{mg} / \mathrm{d}$, either as a supplement or a nanoemulsion, did not change lipoprotein distribution of carotenoids. HDL carried $50-60 \%$ of the serum lutein and zeaxanthin and only $12-15 \%$ of $\alpha$-carotene and $\beta$ carotene.

The particle size of the lutein nanoemulsion (150 $\mathrm{nm})$ was greater than the particle size of nanoformulations of other compounds like ASF, delta-tocopherol and aspirin previously studied in our laboratory by microfluidization process, which were all less than $100 \mathrm{~nm}$ $[14,15,19]$. The reason for the greater than $100 \mathrm{~nm}$ particle size of the lutein nanoemulsion may be the type of surfactant used in the formulation. The nanoformulations mentioned earlier were prepared using $10 \%$ Polysorbate 80 whereas the lutein formulation was prepared using 4\% Phospholipon 85G, a phosphatidylcholine enriched unsaturated phospholipid. The carbon number of the alkyl group in the phosphatidylcholine has a strong correlation with diameter of the particles in the emulsion; a longer carbon chain causes an increase in particle size $[37,38]$. The studies that used polysorbate 80 were all pre-clinical studies or cell culture studies. For human consumption, however, FDA has determined that no more than $360 \mathrm{mg}$ of polysorbate 80 can be ingested per day as an emulsifier for edible fats and oils [39]. Since the present study was done in humans, and concentration of surfactant in the lutein nanoemulsions was $1 \mathrm{~g}$ per serving, polysorbate 80 was not a preferred surfactant. The greater than $100 \mathrm{~nm}$ particle size of the lutein nanoemulsion may also be due to the soybean oil in addition to the phospholipid emulsifier. Nanoemulsions composed of oils containing long chain triglycerides (LCT) have considerably larger particle size (120 $\mathrm{nm}$ ) than nanoemulsions made with low viscosity oils like hexadecane [40].

In conclusion, the present study showed lutein delivered orally as nanoemulsions have greater bioavailability than lutein in a supplement pill form. Also, consumption of up to $6 \mathrm{mg}$ of lutein as a nanoemulsion did not affect absorption of hydrocarbon carotenoids, $\alpha$ carotene and $\beta$-carotene, from the diet. Lutein as a nanoemulsion may not require presence of fat for absorption as it is carried in an oil-phospholipid matrix, however this hypothesis would need further investigation. The preliminary findings from the present study could be used to design larger, more controlled, clinical studies to study lutein nanoemulsion bioavailability and efficacy.

\section{Acknowledgements}

The authors thank the graduate students and staff at the Center for Health and Disease Research at UMass, 
Lowell who volunteered to participate in the study; Donna Rogers and Beth Halaby, UMass Lowell for performing the blood draws; Rosanna Brackett for coordinating with study volunteers and entering diet records; Candice Gendron for entering diet data; Elizabeth F. Goodrow-Kotyla for assistance in conducting the study; Maureen Faul for administrative assistance and Microfluidics Corp., Newton, MA.

\section{References}

1. Klein R, Peto T, Bird A, Vannewkirk MR. The epidemiology of age-related macular degeneration. Am J Ophthalmol 2004; 137: 486-495. doi:10.1016/j.ajo.2003.11.069

2. Resnikoff S, Pascolini D, Etya'ale D, Kocur I, Pararajasegaram R, Pokharel GP, et al. Global data on visual impairment in the year 2002. Bull World Health Organ 2004; 82: 844-851.

3. Nolan J, O'Donovan O, Beatty S. The role of macular pigment in the defence against AMD. AMD 2003; 1: 39-41.

4. Ahmed SS, Lott MN, Marcus DM. The Macular Xanthophylls. Surv Ophthalmol 2005; 50: 183-193. doi:10.1016/j.survophthal.2004.12.009

5. Alves-Rodrigues A, Shao A. The science behind lutein. Toxicology Lett. 2004; 150: 57-83. doi:10.1016/j.toxlet.2003.10.031

6. Roodenburg JC, Leenen R, van het hof $\mathrm{KH}$, Weststrate JA, Tijburg LBM. Amount of fat in the diet affects bioavailability of lutein esters but not of $\alpha$-carotene, $\beta$-carotene, and vitamin E in humans. Am J Clin Nutr 2000; 71: 1187-93.

7. Parker RS. Absorption, metabolism, and transport of carotenoids. FASEB J 1996; 10: 542-551.

8. Chung HY, Rasmussen HHM, Johnson EJ. Lutein bioavailability if higher from lutein-enriched eggs than from supplements and spinach in men. J Nutr 2004; 134: 1887-1893.

9. Handelman GJ, Nightingale ZD, Lichtenstein AH, Schaefer EJ, Blumberg JB. Lutein and zeaxanthin concentrations in plasma after dietary supplementation with egg yolk. Am J Clin Nutr 1999; 70: 247-51.

10. Goodrow EF, Wilson TA, Houde SC, Vishwanathan R, Scollin PA, Handelman GJ, Nicolosi RJ. Consumption of one egg per day increases serum lutein and zeaxanthin concentrations in older adults without altering serum lipid and lipoprotein concentrations. J Nutr 2006; 36: 2519-2524.

11. Vishwanathan R, Goodrow-Kotyla EF, Wooten BR, Wilson TA, Nicolosi RJ. Consumption of 2 and 4 egg yolks/d for 5 wk increases macular pigment concentrations in older adults with low macular pigment taking cholesterollowering statins. Am J Clin Nutr 2009; 90: 1272-9. doi:10.3945/ajen.2009.28013

12. Tadros T, Izquierdo P, Solans C. Formation and stability of nano-emulsions. Adv Colloid Interface Sci 2004; 108-109: 303-318. doi:10.1016/j.cis.2003.10.023

13. Chen H, Weiss J and Shahidi F. Nanotechnology in nutraceuticals and functional foods. Food Tech 2006;1: 303 6

14. Kotyla T, Kuo F, Moolchandani V, Wilson TA, Nicolosi RJ. Increased bioavailability of a transdermal application of a nano-sized emulsion preparation. Int J Pharm 2008; 347: 144-148. doi:10.1016/j.ijpharm.2007.06.045

15. Kuo F, Subramanian B, Kotyla T, Wilson TA, Yoganathan S, Nicolosi RJ. Nanoemulsions of an anti-oxidant synergy formulation containing gamma-tocopherol have enhanced bioavailability and anti-inflammatory properties. Int $J$ Pharm 2008; 363: 206-13. 이:10.1016/j.ijphar m.2008.07.022
16. Tiwari SB, Amiji MM. Improved oral deliver of paclitaxel following administration in nanoemulsion formulations. $J$ Nanosci Nanotechnol 2006; 6: 3215-21. doi:10.1166/jnn.2006.440

17. Tagne JB, Kakumanu S, Ortiz D, Shea T, Nicolosi RJ. A nanoemulsion formulation of tamoxifen increases its efficacy in breast cancer cell line. Mol Pharm 2007; 5: 280-286. doi:10.1021/mp700091j

18. Tagne JB, Kakumanu S, Nicolosi RJ. Nanoemulsion preparations of the anti-cancer drug dacarbazine significantly increases its efficacy in a xenograft mouse melanoma model. Mol Pharm 2008; 5: 1055-1063. doi:10.1021/mp8000556

19. Subramanian B, Kuo F, Ada E, Kotyla T, Wilson TA, Yoganathan S, Nicolosi RJ. Enhancement of antiinflammatory property of aspirin in mice by a nanoemulsion preparation. Int Immunopharm 2008; 8: 15331539. doi:10.1016/j.intimp.2008.06.009

20. Thurmann PA, Schalch W, Aebischer JC, Tenter U, Cohn W. Plasma kinetics of lutein, zeaxanthin, and 3-dehydrolutein after multiple doses of a lutein supplement. $A m J$ Clin Nutr 2005; 82: 88-97.

21. Handelman GJ, Snodderly DM, Adler AJ, Russett MD, Dratz EA. Measurement of carotenoids in human and monkey retinas. Methods Enzymol 1992; 213: 220-30. doi:10.1016/0076-6879(92)13123-F

22. Steghens JP, van Kappel AL, Riboli E, Collombel C. Simultaneous measurement of seven carotenoids, retinol and alpha-tocopherol in serum by high-performance liquid chromatography. J Chromatogr B Biomed Sci Appl 1997; 694: 71-81. doi:10.1016/S0378-4347(97)00140-0

23. Allain CC, Poon LS, Chan CSG, Richmond W, Fu PC. Enzymatic determination of total serum cholesterol. Clin Chem 1974; 20: 470-5.

24. McGowan MW, Artiss JD, Strandbergh DR, Zak B. A peroxidase-coupled method for the colorimetric determination of serum triglycerides. Clin Chem 1983; 29: 538-42.

25. Snedecor GW, Cochran WG, Ames IA. Statistical methods. The Iowa State University Press, 1980.

26. US Department of Agriculture. A R S. Nutrient Data Laboratory [homepage on the internet]. 1998 [cited 11/05], Available http://www.nal.usda.gov/fnic/foodcomp/search/.

27. Chen HS, Chang JH, Wu JSB. Calcium bioavailability of nanonized peal powder for adults. J Food Sci 2008; 73: 246-251. doi:10.1111/j.1750-3841.2008.00965.x

28. Hatanka J, Kimura Y, Lai-Fu Z, Onoue S, Yamada S. Physicochemical and pharmacokinetic characterization of watersoluble coenzyme Q(10) formulations. Int J Pharm 2008; 363: 112-7. doi:10.1016/j.ijpharm.2008.07.019

29. Reis P, Ribeiro AJ, Houng S, Veiga F, Neufeld RJ. Nanoparticulate delivery system for insulin: design, characterization and in vitro/in vivo bioavailability. Eur J Pharm Sci 2007; 30: 392-397. doi:10.1016/j.ejp s.2006.12.007

30. Pires LA, Hegg R, Valduga CJ, Graziani SR, Rodrigues DG, Maranhao RC. Use of cholesterol-rich nanoparticles that bind to lipoprotein receptors as a vehicle to paclitaxel in the treatment of breast cancer: pharmacokinetics, tumor uptake and a pilot clinical study. Cancer Chemother Pharmacol 2009; 63: 281-287. doi:10.1007/s00280-008-0738-2

31. De Smidt PC, Campanero MA, Troconiz IF. Intestinal absorption of penclomedine from lipid vehicles in the conscious rat: contribution of emulsification versus digestibility. Int $J$ Pharm 2004; 270: 109-118 doi:10.1016/j.ijpharm.2003.10.036

32. Borel P, Grolier P, Armand M, Partier A, Lafont H, Lairon $\mathrm{D}$, Azais-Braesco V. Carotenoids in biological emulsions: 
solubility, surface-to-core distribution, and release from lipid droplets. J Lipid Res 1996; 37: 250-261.

33. Roodenburg AJC, Rianne L, van het Hof $\mathrm{KH}$, Weststraten JA, Tijburg LBM. Amount of fat in the diet affects bioavailability of lutein esters but not of $\alpha$-carotene, $\beta$-carotene, and vitamin $\mathrm{E}$ in humans. Am J Clin Nutr 2000; 71: 1187793.

34. Tanumihardjo SA, Li J, Dosti MP. Lutein absorption if facilitated with cosupplementation of ascorbic acid in young adults. J Am Diet Assoc 2005; 105: 114-118. doi:10.1016/i.jada.2004.10.011

35. Molldrem KL, Li J, Simon PW, Tanumihardjo SA. Lutein and $\beta$-carotene from lutein-containing yellow carrots are bioavailable in humans. Am J Clin Nutr 2004; 80: 131-136.

36. Tyssandier V, Cardinault N, Caris-Veyrat C, Amiot MJ, Grolier P, Bouteloup C, Azais-Braesco V, Borel P. Vegetable-borne lutein, lycopene, and $\beta$-carotene compete for incorporation into chylomicrons, with no adverse effect on the medium-term (3-wk) plasma status of carotenoids in humans. Am J Clin Nutr 2002; 75: 526-34.
37. Nii T, Ishii F. Dialkylphosphatidylcholine and egg yolk lecithin for emulsification of various triglycerides. Colloids Surf B Biointerfaces 2005; 41: 305-311. doi:10.1016/j.colsu rfb.2004.12.017

38. Ishii F, Nii T. Properties of various phospholipid mixtures as emulsifiers or dispersing agents in nanoparticle drug carrier preparations. Colloids Surf B Biointerfaces 2005; 41 257-262. doi:10.1016/j.colsurfb.2004.12.018

39. Code of Federal Regulations. 2008. 21CFR172.840.

40. Wooster TJ, Golding M, Sanguansri P. Impact of oil type on nanoemulsion formation and Ostwald ripening stability. Langmuir 2008; 24: 12758-12765. doi:10.1021/la801685v

Received 10 November, 2009; accepted 6 December, 2009; published online 9 December, 2009.

Copyright: (c) 2009 R. Vishwanathan et al. This is an openaccess article distributed under the terms of the Creative Commons Attribution License, which permits unrestricted use, distribution, and reproduction in any medium, provided the original author and source are credited. 